\title{
Teaching Research Methodology: Student-centered Approach Computing Education Undergraduate Course
}

\author{
Ignitia Motjolopane ${ }^{1 *}$ \\ ${ }^{1}$ Department of Information Systems, North-West University Mafikeng Campus Private Bag X2046 Mmabatho 2745, South Africa
}

\begin{abstract}
Teaching research methodology is one of the core components of various degree programs. Scholarship around teaching research methodology is beginning to grow with most work concentrated in Social Work, Health, Social Science, and limited work in the area computing education. This paper presents a reflection on adopting a student centred approach towards teaching research methodology course to three different groups of fourth level university students. In this paper the strategies for facilitating deep learning in teaching research methods and research methods in the Information Systems domain will be discussed. In addition, reflections on the use of a student centred approach, student experiences and strategies used. The experiences and strategies relate to facilitating deep learning. The experiences are focused on topic identification, conducting, and writing up the literature reviews, developing an understanding of the research methodology inclusive of data analysis and presenting the research report.
\end{abstract}

\section{1- Introduction}

Universities play an important role in society through three basic missions of teaching, research, and public service [1]. Therefore, Barnet and Bengtsen [2] highlight that universities are a space for knowledge creation through research and for understanding of the said knowledge through teaching and learning. Moreover, the production of a piece of research is one of the key differentiators between academic education and vocational education. The research methodology course beyond teaching the students how to conduct research has the potential for teaching students reallife thinking and reasoning skills that may be useful in various settings [3]. Consequently, the university space mandates for teaching research methodology in a manner that students develop deep approaches to learning as Hall, Ramsay and Raven [4] suggest that deep approaches to learning are claimed to enhance students' engagement with their subject material and result in improved analytical and conceptual thinking skills. In addition, a research methodology course has the potential to assist students to develop 21st century communication skills as students need to present their research effectively in both oral and written format. Therefore, the instructional strategies used should allow for the development of these literacies [5]. Furthermore, research methodology plays an important role in finding solutions to real-world problems and the discovery of truth with teaching research skills undergraduate students assisting in preparing students for post-graduate studies [6]. The capacity building in social science research methods is positioned by some governments and research councils as crucial to global competitiveness [7]. However, as Alharbi [8] indicates, research methods are one of the challenging university courses to teach, with lecturers often encountering challenges. In a similar manner, Mullins [9] indicates that teaching research methods can be challenging for many educators with students being apprehensive about research methodology content.

* CONTACT: Ignitia.motjolopane@nwu.ac.za

DOI: http://dx.doi.org/10.28991/esj-2021-01255

(C) 2021 by the authors. Licensee ESJ, Italy. This is an open access article under the terms and conditions of the Creative Commons Attribution (CC-BY) license (https://creativecommons.org/licenses/by/4.0/). 
A well-known primary challenge in teaching research methodology is how to make the course interesting to students [6]. Another hurdle faced in teaching research methodology is that many students at both undergraduate and graduate levels possess a weak foundation for conducting research making the course challenging both to the instructors and students [10]. Furthermore, students are faced with the problem of having to read a large number of articles to gain an overview of current research in the area of interest and the methods used to determine the contribution of own research findings to the knowledge in the field [5]. The reading challenges are exacerbated by language and writing style used in academic papers that students often find unfamiliar, difficult to comprehend and understand. Moreover, students find having to read the large number of articles overwhelming and at times feel it was not meaningful to read the articles [5]. An additional inherent challenge in teaching research relates to the diversity of student academic backgrounds [11]. Despite research methodology skills being applicable to daily problems to systematically provide thoughtful solutions [6], students often do not see the practical relevance of the research methods course [12], nor the link to the degree that they are pursuing. Moreover, similar to other university courses, lecturing is the most employed tool for facilitating research methods learning, which, according to Thomas and Brown [13]. They implicitly assumes that the instructor has valuable, stable knowledge to pass on to students, but in the current and changing environment, knowledge is dynamic. Therefore, Schmidt et al. [14] add that lecturers do not promote critical thinking and cognitive engagement and are based on the information transmission fallacy that students learn by being told. Furthermore, Hosein and Rao [15] indicate that despite the emphasis on student-centered pedagogical approaches, undergraduate research methods' pedagogy remains surprisingly teacher-directed. In addition, the development of excellence in the teaching of research methods has been that the development of advanced methods training has frequently been the task of methodological experts who do not have a pedagogic background [7].

Despite challenges in teaching research methodology, historically, the area has received little attention in academic research [16]. According to Steenkamp and McCord [17], in computing research, the subject matter is varied covering areas such as technology, processes and human aspects relating to technology. Furthermore, computing research's main focus is on how information systems as a sociotechnical system may be effectively deployed to improve the human conditions within which the uses of information technology may be evaluated [18]. The broad nature of research in the area suggests varied approaches to research. Consequently, researchers in the computing research, when planning research projects, may choose from a range of methodologies most of which are originally derived from research done in other fields such physical, economic, and social sciences [17]. Moreover, Scholtz [19] indicates that in computing research methodology, primary challenges reported related to over-dependence on supervisors, writing skills, critical reflection and confusion regarding the wide array of research methodologies. As such, a few challenges in teaching research methodology in the other fields are of relevance in facilitating research methodology learning in information systems and information technology. Lewthwaite and Nind [7] highlight that research methods instructors face additional challenges in teaching research methods as methodological expertise is often fragmented across academic disciplines. Furthermore, Gunn's [20] wide range of social science subjects can learn from each other, by identifying good practice from a wide range of studies, but the practices would need to be tailored to individual disciplines. In addition, senior academics and scholars with significant experience of teaching advanced methods at postgraduate level have alluded to the importance of connecting learners to research, giving direct and immersive experiences of research practice and promoting reflexivity [7]. As such, Mathur [21] recommends that the approach to teaching research methodology needs to be interactive, friendly, rigorous and result oriented. Therefore, in addressing these and the inherent challenges in teaching research methodology and its importance, there is a need to shift from a teacher-centric to student-centric approach to enhance student engagement and active learning. As a student-centered approach moves away from an instructor transferring information about research methodology to rather a creation of an interactive environment where students master technical information through experience, reflection, and critical analysis [6]. Furthermore, studentcentered teaching methods should be promoted in teaching research methodology [22] and methods are perceived as one of the factors that were valuable in decreasing anxiety related to learning research methodology and enhancing student learning [23].

Student-centered learning may be of even greater importance in the current emergency remote learning that is defined as usually unplanned shift from teaching into a remote situation such as the Coronavirus outbreak with the expectation that after the emergency state, everything is supposed to go back to normalcy [24]. One of the main pitfalls in emergency remote learning is high trust is placed in the technology enhanced learning processes with a focus on learner engagement as an afterthought and teaching in emergency remote learning calls for a pedagogy of care, not on purely didactic taking into account many variables that include target group, age range, technological infrastructure, and social and economic context [25]. For example, according to Hodges et al. [26], choices around synchrony are dependent on learners' characteristics and what best meets their needs with adult learners suited to more flexibility, so asynchronous is usually best, perhaps with optional synchronous sessions, whereas younger learners benefit from the structure of required synchronous sessions. 


\section{2- Student Centered Learning Literature Review}

\section{2-1-Defining Student Centered Learning}

Defining student-centered learning may pose a challenge, as O'Neill and McMahon (2005) highlight that the term 'student-centered learning' is overused and could mean different things to different people. Moreover, according to Guzman (2016) [27], the challenge in defining student-centered learning is compounded by the fact that scholars use up to 11 different names to refer to student-centered learning, such as active learning, collaborative learning, inquiry-based learning, problem-based learning, peer-led team learning, peer instruction, inquiry-guided learning and project-based learning. These different names, besides active learning, seem to refer to the different strategies that one may use to facilitate student-centered learning. Therefore, student-centered learning may also be called active learning. The table below represents a sample definition of student-centered learning.

Table 1. Student-centered learning definitions.

\begin{tabular}{ll}
\hline \multicolumn{1}{c}{ Reference } & \multicolumn{1}{c}{ Student-centered learning definitions } \\
\hline Guzman (2016) [27] & $\begin{array}{l}\text { An instructional approach in which students influence content, activities, materials, and pace of learning } \\
\text { An educational approach that replaces traditional lectures with active learning, self-learning, group learning and } \\
\text { ultimately empowers students to take responsibility for own education becoming lifelong learners rather than learning } \\
\text { by means of spoon-feeding education } \\
\text { [28] }\end{array}$ \\
$\begin{array}{l}\text { Approach to education focusing on the interests of students rather than those involved in the educational process such } \\
\text { as teachers and administrators }\end{array}$ \\
$\begin{array}{l}\text { Mitchell et al. (2017) [30] } \\
\text { One time or ongoing student exercise that is introduced in classrooms to encourage student thinking and participation } \\
\text { to engage students in the learning process } \\
\text { (1991) [31] }\end{array}$ \\
$\begin{array}{l}\text { Instructional activities involving students in doing things and thinking about what they are doing } \\
\text { The reliance on active rather than passive learning, emphasizing deep learning and understanding, with increased } \\
\text { responsibility and accountability on the part of the student, increased sense of autonomy in the learner, interdependence } \\
\text { between teacher and learner, mutual respect within the learner teacher relationship and reflexive approach to the } \\
\text { teaching and learning process on the part of both teacher and learner. }\end{array}$ \\
\hline
\end{tabular}

These various definitions were compared and synthesized and in this paper student-centered learning is used to refer to: "A teaching approach that seeks to develop life-long learning and critical thinking by moving from the traditional lecture approach of spoon feeding to active learning through doing and thinking, emphasizing deep learning, increased student responsibility, autonomy and accountability for learning and ongoing reflection from both the teacher and the student."

\section{2-2-Student-centered Learning Benefits and the Required Key Changes to Teaching Practice}

Student centered learning is appealing to universities and, according to Liard et al. [33], a growing body of research suggests that educationally effective learning environments are characterized by the promotion of deep approaches to learning. Therefore, Guzman (2016) [27] suggests that using student-centered learning facilitates self-directed learning with educators ensuring learning is experienced and competency-based learning excels. Consequently, colleges and universities are paying increased attention to the benefits of student-centered approaches to teaching and learning [33]. Moreover, when instructors use student-centered approaches, students engage thoughtfully with course material both inside and outside the classrooms [30]. In addition, student-centered learning promotes different types of thinking such as analytical, critical, reflective and creative as well as supporting conceptual understanding and retention of knowledge self-directing and regulating learners [27], which are key skills and competencies required for the 21 st century students. According to Mandel [34], a major factor in the success of a student-centered research methodology course is the availability of the instructor to the students throughout the semester and the instructor's responsiveness to student needs in a new approach to a difficult course. In addition, Gunn [20] cautions against wholeheartedly embracing studentcentered learning without acknowledging the approach's limitations or thinking critically about how the approach should be used.

Student-centered learning requires key changes to the practice of teaching and learning, and, according to Weimer [35], these five key changes entail the balance of power, the function of content, the role of teacher the responsibilities of the student and the purpose and process of evaluation. The balance of power relates to the sharing of power between students and teachers with the power distributed in amounts and proportion to the student's ability to handle the power as opposed to a wholesale transference of power that might lead to teacher's violation of the given legitimate power. In student-centered learning, the content is not an end, but a means to an end that is used to facilitate learning the specific body of knowledge, as a vehicle to develop learning skills to promote student self-awareness and confidence on a continuous basis. Furthermore, Weimer [35] highlights that the role of the teacher is to redistribute power and to facilitate learning within individual and collective contexts by connecting students and resources, while designing activities and assignments that engage students, as well as modelling for the novice students how difficult material may be accessed, 
explored, and understood. Furthermore, the role of the teacher is of increased importance as student-centered pedagogies require the teacher to strike a balance between didactic and active pedagogies based on particular circumstances [20]. As such, the teacher's role is to guide and provide students with multiple activities and teaching materials [22].

The other requisite change is in the responsibility of the student; responsibility for learning shifts to the student, and therefore the methods of content delivery need to provide students with the opportunity to take control of learning and to be actively involved in the learning process [35]. Therefore, students learn through active participation in the process with students taking ownership of own learning [22]. In student-centered learning, the process and purpose of assessment have to change. Weimer [35] suggests that assessment should not be used only to generate grades, but more focused on promoting learning with educators still evaluating and grading student work, but evaluation activities that involve students are included in the process both in assessing own work and participating in evaluation of work done by peers. Consequently, a variety of tools are used to evaluate and assess different aspects of learning, therefore addressing challenges on the assumption that grades measure learning and the subjective nature of grades. These five key areas of change to teaching practices, as drawn from Weiner [35], are balance of power, function of content, role of the teacher, responsibilities of the student and the purpose and process of evaluation, and are illustrated in Figure 1. The five key areas of change serve as a comprehensive guideline for assessing the extent to which facilitation in research methodology courses has shifted from a teacher-centered approach to a student-centered approach.

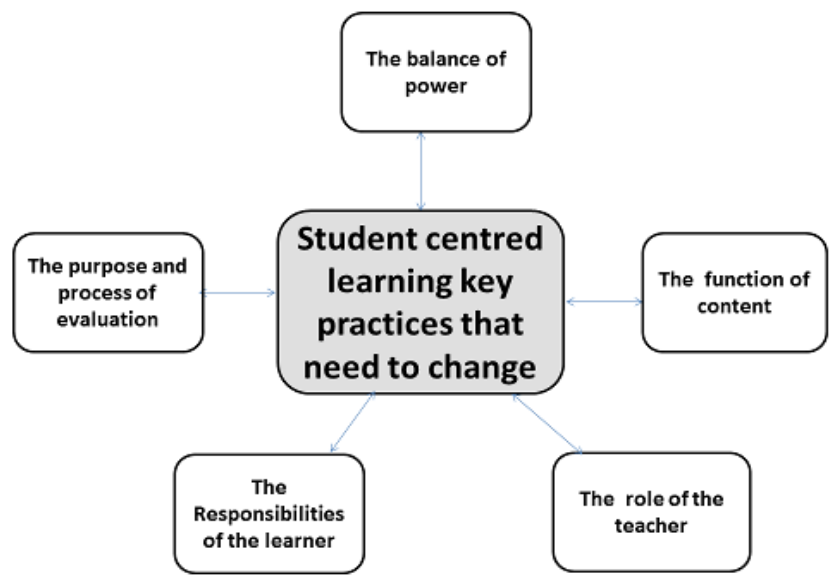

Figure 1. Student-centered learning key practices that need to change.

\section{2-3-Teaching Research Methodology Student-centered Approaches}

Student-centered approaches are not positioned as a panacea for teaching research methodology, as Schutt et al. [36] highlight that, despite being no pedagogical panacea to eliminate all difficulties in teaching the introductory methods course, instructional efforts may be substantially improved. As such, student-centered approaches are suggested to enhancing student learning in research methodology. Teoh et al. [37] indicate the need to re-look students' engagement in research methodology. In teaching a research methodology course, there are emerging examples of using studentcentered approach; however, Mathur [21] indicates that often lecturers are not aware of the recent developments in pedagogy that impact teaching research methodology. Furthermore, according to Aguado [10], there are different goals for research methods training among institutions, departments, and at instructor level with these goals leading to variety emphasized on various aspects of research methodology. For example, some may emphasize the diversity of social sciences, and the types of questions asked in various sub-disciplines, while others might advocate epistemology and the need to understand the role of scientific knowledge. Examples of goals that were pursued in teaching research methodology across the disciplines include Aguado [10], who draws from Confucius "I hear and I forget. I see and I remember. I do and understand" to adopt hands on approach that facilitates for students to gain practical knowledge of how research is done." Another example is that of Mandel [34], whose master's research methodology course was aimed at demonstrating the relevance of research methodology course to the core curriculum. This was facilitated by students completing a research project for a client over one semester. According to Mandel [34], the approach that was used beyond addressing the students' concerns regarding the relevance of the research methodology course and learning more skills, as one student said "the real application of the concept increased my understanding, making me a better researcher and interpreter of other's research".

In generalizing the student-centered approaches, according to Schmidt et al. [14], all approaches to active learning during lectures assume that students first acquire knowledge individually, either through pre-reading or through short presentations by lecturers in class. Often, project-based learning is a model used to organize learning around projects with projects referring to complex tasks, based on challenging questions or problems, which involve students in design, problem-solving, decision-making, or investigative activities, providing students the opportunity to work relatively autonomously over extended periods of time; and culminate in realistic products or presentations [6]. Strategies that 
instructors could use include incorporating active learning assignment, cross-methods and cross-discipline guest discussion facilitators, focus on research in the real world and fostering faculty teaching and collaboration [38].

The use of tools such as referencing software like Endnote and Mendeley is valuable in supporting student-centered approaches and not only giving students practical guidance, but with some students finding the use of tools as contributing to making the course interesting. Another tool that has potential for systematic identification of research problems and supporting effective literature reviews is proposed by Sturn et al. [39], i.e. a LitSonar tool to enhance the efficiency of the process while maintaining and improving validity and reliability meta search engine for academic literature review that unifies access to high quality content from numerous literature databases. Furthermore, the use of artificial intelligence to support literature search is presenting viable opportunities for students to conduct in-depth analyses. For example, the Iris.ai tool supports literature analysis with a core database of $77 \mathrm{M}$ open access papers and finds the ones that best match topics of interest and categorizes the information and uses co-citations to identify research opportunities [40] .

\section{3- Research Methodology using Student-centered Approach Strategies and Student Experiences}

An initial literature search used Google Scholar to identify the most cited and most recent articles in the area using a combination of the following phrases: "teaching research methodology, student-centered learning, computing education and information technology". The subsequent step was a search in the academic electronic databases that included Emerald, Science Direct, IEEE, Springer and EBSCOHost. Additional sources were identified from the citations in the papers that were reviewed. These search strategies led to 82 potential articles.

The articles, abstracts and conclusions were scanned, and those not focusing on teaching research methodology but other aspects of research methodology such student attitudes towards research methodology courses and the use of student-centered learning to teach other courses were removed. The resulting 57 articles were analyzed to identify those articles that use the student-centered approach using the various names such as active learning, experiential andragogy and JigsawTechnique student-centered learning and collaborative work. Even those that used blended learning and gamification but adopted a student-centered activities and approaches were included in the final analysis. Some of those that were excluded for not using student-centered approach, but may be incorporated to enhance student-centered learning included Daniel [41], who advocates for reimaging research methodology programs to enable students to develop appropriate competences to deal with the challenges of working with complex and large amounts of data and associated analytics. Furthermore, approaches for normalizing failure as part of the research process providing students with an opportunity to experience and discuss failures well before they go off to conduct independent therefore within the context of empirical fieldwork [42] is a key area for introductory research methodology courses. The remaining 36 that adopted student-centered learning were analyzed to determine the course goals, approaches to topic discovery, literature review, research methodology, writing the research report and the extent to which the courses embed the five key changes to practices. The research methodology is illustrated in Figure 2.

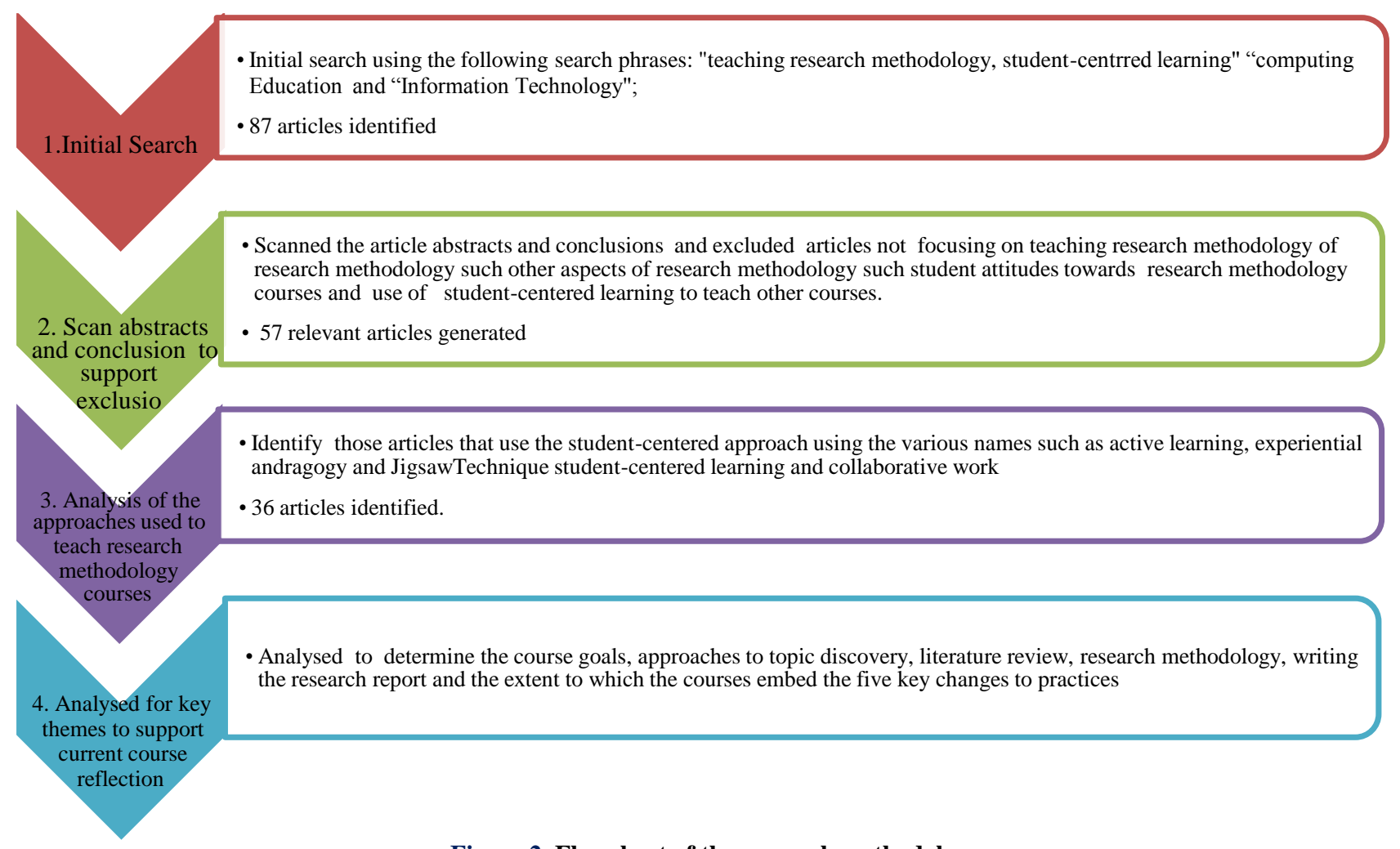

Figure 2. Flowchart of the research methodology. 


\section{4- Results}

\section{4-1-Reviews on Student-centered Approaches and the Key Practices Research Methodology Teaching}

Based on the current review on the student-centered approaches in teaching research methodology, one may suggest that while Schutt et al. [36] made the call for eliminating difficulties in teaching introductory research methodology course papers addressing the challenge are growing with the highest number of articles published in 2018. This information is illustrated in Figure 3.

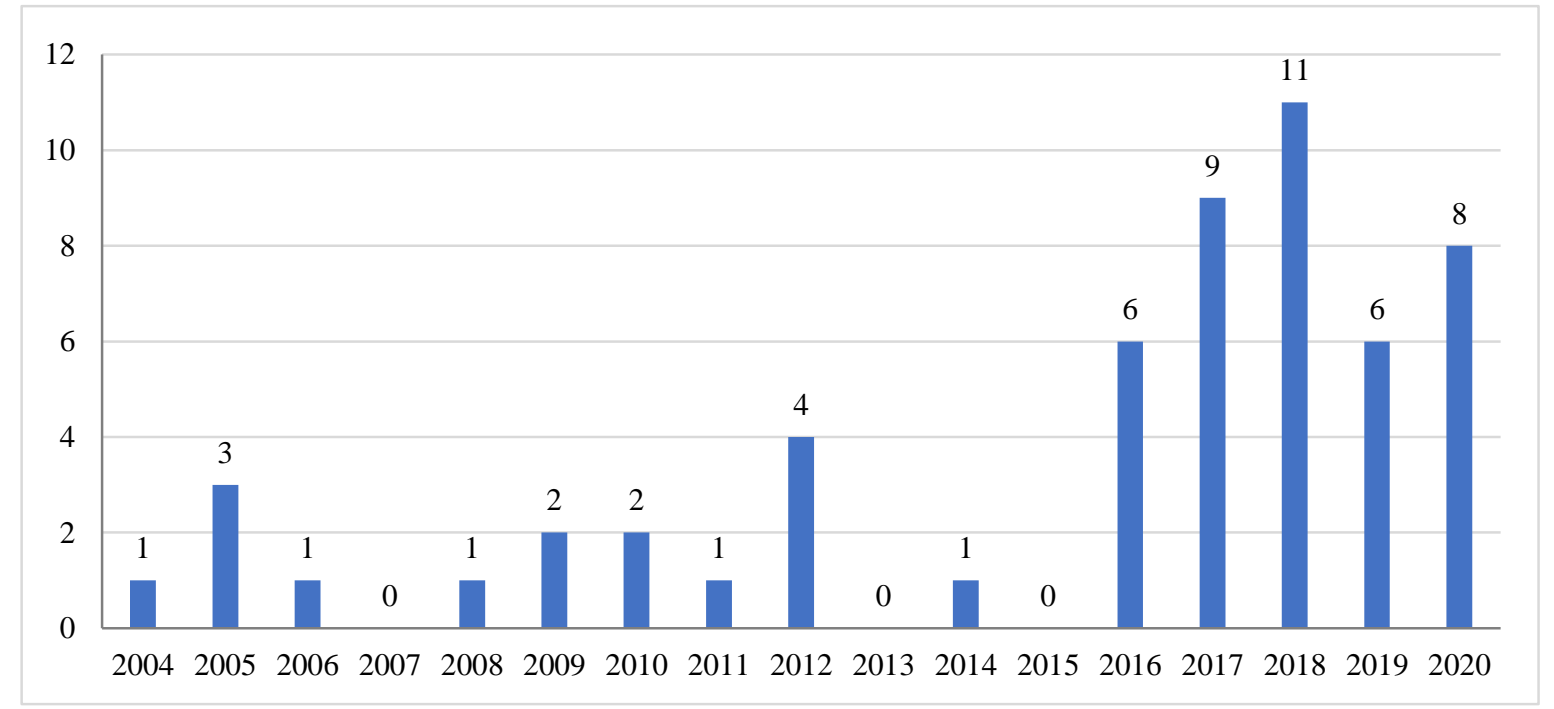

Figure 3. Publications teaching research methodology.

\section{4-2-Reflection}

The reflection is based on teaching research-methodology to undergraduate students in Computing. The instructor's main goal is to use a student-centered approach to demonstrate the relevance for research to the overall degree program while ensuring that students develop critical thinking and acquire skills to become life-long learners prepared to conduct work-related research and building a foundation for further studies. A student-centered approach that is used includes a mix of face-to-face lectures that incorporate the instructor's presentations of research methodology concepts, assignment, and students' presentations, as well as group supervision of ten students per group to cater for the large group, where the students get a chance for the instructor to look at each student's status of work towards the final product and clarify issues for students.

\section{4-2-1- Topic Discovery and Research Problem Formulation}

As a first assignment, students choose a topic within the information technology area as a focus point for the eventual empirical research. The emphasis is on selecting a topic that is related to each individual growth aspirations in the information technology industry such that the student can use the research to know more about the area of interest and identify challenges in the area. This first assignment entails using Google Scholar to search five most cited articles and five most recent. These articles are read and captured using benefits tables and literature review tables. The tables are submitted in groups of ten students per group to the instructor every Wednesday by 11:59 PM allowing the instructor to review the work of each student and choose two students from each group to present in the Saturday weekly sessions. These tables are updated on a weekly basis and support students' identification of research problem and writing the introduction to the study. In this process the topics that were identified included broad areas in computing research such as cloud computing, e-learning, mobile learning inclusive of workplace e-learning. Interest in business Intelligence and big data analytics was another common research area. Furthermore, students were selecting to explore artificial intelligence topics such as smart home, robotics and automated processes and smart road detection technologies, and Internet of Things. Information systems success whilst being one of the historic research areas in computing was still of interest with students examining success of systems such as online registration, grant management systems and customer relationship management systems. The selected topics are depicted in the Figure 4. 


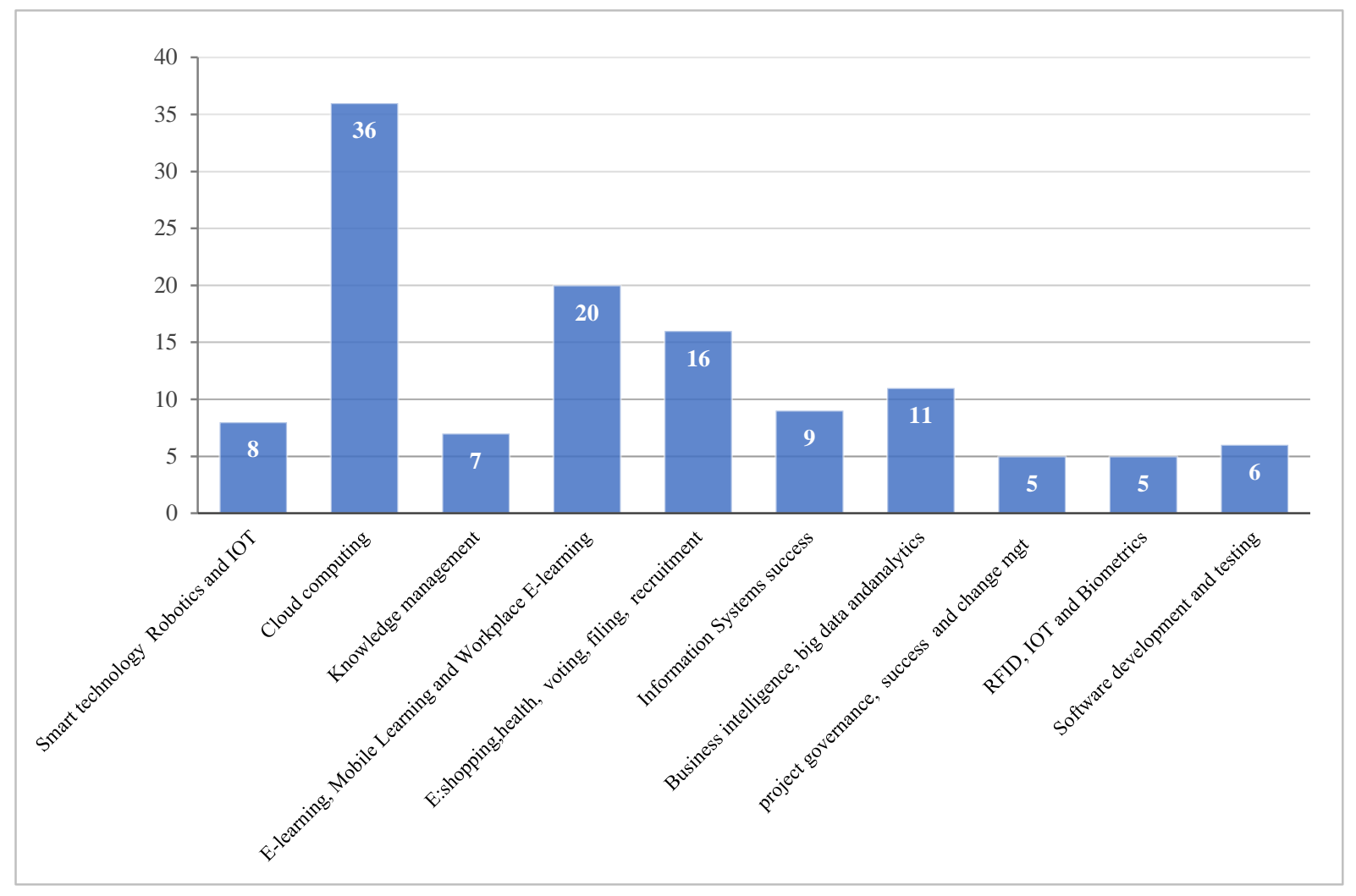

Figure 4. Ten (10) most selected topics by students.

\section{4-2-2- Conducting and Writing Literature Review}

Once the students have identified the research problem and questions, the weekly tables are used for the continuous updates of the literature review tables. Therefore, students are still covering a substantial amount of academic material but get the opportunity to write the final product on an ongoing basis. As a way for the instructor to exercise control and ensure the module objectives are met, the students must choose a recent article that has a conceptual framework or theoretical for testing in the student's environmental context. Therefore, the literature review table focus is on reading and writing on the components of the conceptual framework enabling sufficient material to be covered so as to be in the position to generate research questionnaire in the second part of the module.

\section{4-2-3- Developing an Understanding of the Research Method Inclusive of Data Analysis}

The main tool that is used to support the students' understanding of the layers of research methodology is the Saunders, Lewis and Thornhill [43] research onion that was adapted to cover only the positivist and interpretivist paradigms. The students were exposed to conducting research using both paradigms, but for the individual research projects, students conduct positivist research due to the time constraints that they must cope with in terms of data collection. Peeling the onion is one area that the students found challenging in the beginning, but as the students continually peeled the onion, they could gradually comprehend the nuances around philosophy epistemology and ontology and how these influence the research methods, strategies, sampling data and design as well as research ethics. This section of the course benefited immensely through students' own reading of research textbooks resulting in some students going beyond developing an understanding of positivist and interpretivist paradigms but extending knowledge to other paradigms such as pragmatism and design science.

\section{4-2-4- Writing the Research Report}

Writing the proposal and the research report is treated as a continuous process throughout both semesters as using weekly assignments and the mark submission assignment as input and final presentation where students share research findings. Academic writing was found to be one of the areas that students find quite challenging and especially moving away from author-centric to a concept-centric approach and the use both in-text citations and references. The use of Endnote for which students received training and support from the library as well as from the instructor appears to be one of the key factors contributing to success. The collaboration between the library and the instructor proves to be valuable in terms of assisting students in learning how to access online databases off campus as these are part-time students. 


\section{5- Implications}

While the approach seeks to adopt a student-centered approach to teaching research methodology similar to other approaches presented in the literature on using student-centered approaches to teaching research methods, the approach adopted falls short in terms of fully embedding five key changes to practices. The approach attempts to address the balance of power with the students having the choice of topic to conduct the research with the instructor's guidance. Despite the limitation, the approach was able to achieve the objective of illustrating relevance of research to a real work situation, thereby being able to generate motivation and interest for the students and prepare them for further studies with a majority of students expressing desire to undertake further research studies in the future. The adopted approach made efforts to use content to facilitate learning in research methods and as a vehicle to promote student self-awareness and confidence. As one student had found the writing skills attained as part of the course valuable when writing work related reports and being asked to teach her colleagues how to write reports. An example of the confidence that one student shared was that in the working environment some of the colleagues are pursuing research-related studies and is a sort of 'reference' in research-related aspects to the colleagues.

The role of the teacher and the library services served as valuable tools in terms of connecting students to resources mainly online academic databases. However, more needs to be done in shifting more responsibilities to the students such as the use of blended learning in future offerings. As used to previously support part-time students by Venegas et al. [44], where teaching materials are available online and each group was given a forum and a wiki. The use of blended learning would enable students review lesson and complete exercise that will be captured on the learning management system linked to individual students thereby enabling the instructor to monitor and support students' progress before face-to-face sessions. This approach would allow for more time for group supervision, which is one of the tools that the students seem to prefer, but is limited mainly due to the student-teacher ratio as well as the use of face-to-face sessions to cover the technical components of the course.

The use of the literature review tables while supported the active learning and supporting students with making progress on own work has the potential to be enhanced with the use of tools such LitSonar and Iris.ai. as basis of conducting effectiveness literature review and creative identification of the research problems. The purpose and process of assessment tried to align with student-centric approach promoting ongoing learning and often students being given the opportunity to redo and resubmit the work. However, there was limited opportunity involving students in the process both in assessing own work and participating on evaluation of work done by peers. As such, this limitation would need to be addressed in future offerings of the course.

\section{6- Conclusion}

In this paper, a review and reflection using a student-centered approach to teaching research methods to fourth-level students are presented. The paper also presented what student-centered learning is, as well as examples of previous approaches to teaching research methodology using student-centered approaches. The paper also shared the strategies used to facilitate deep learning and life-lifelong learning in teaching research methodology and a reflection of student experiences and lessons learned and potential areas of future improvement in adopting the student-centered approaches. An evaluation of the five key changes to facilitate student-centered learning has been outlined. Further study would focus on examining detailed examination of students' experiences using student feedback from the modules as well as ways to ensure a comprehensive approach to embedding the five requisite key change to teaching practice teaching research methodology for fourth-level computing students.

\section{7- Declarations}

\section{7-1- Funding}

The author(s) received no financial support for the research, authorship, and/or publication of this article.

\section{7-2-Conflicts of Interest}

The author declares that there is no conflict of interests regarding the publication of this manuscript. In addition, the ethical issues, including plagiarism, informed consent, misconduct, data fabrication and/or falsification, double publication and/or submission, and redundancies have been completely observed by the authors.

\section{8- References}

[1] Pucciarelli, Francesca, and Andreas Kaplan. "Competition and Strategy in Higher Education: Managing Complexity and Uncertainty.” Business Horizons 59, no. 3 (May 2016): 311-320. doi:10.1016/j.bushor.2016.01.003.

[2] Barnett, Ronald, and Søren Bengtsen. "Universities and Epistemology: From a Dissolution of Knowledge to the Emergence of a New Thinking.” Education Sciences 7, no. 1 (March 6, 2017): 38. doi:10.3390/educsci7010038. 
[3] VanderStoep, Scott W., and John J. Shaughnessy. "Taking a Course in Research Methods Improves Reasoning About Real-Life Events.” Teaching of Psychology 24, no. 2 (April 1997): 122-124. doi:10.1207/s15328023top2402_8.

[4] Hall, Matthew, Alan Ramsay, and John Raven. "Changing the Learning Environment to Promote Deep Learning Approaches in First-Year Accounting Students.” Accounting Education 13, no. 4 (December 2004): 489-505. doi:10.1080/0963928042000306837.

[5] DeWitt, D., and N. Alias. "Infographic Posters for Enhancing 21st Century Communication Skills." (2017): 1-18.

[6] Braguglia, Kay H., and Kanata A. Jackson. "Teaching Research Methodology Using A Project-Based Three Course Sequence Critical Reflections On Practice.” American Journal of Business Education (AJBE) 5, no. 3 (May 1, 2012): $347-352$. doi:10.19030/ajbe.v5i3.7007.

[7] Lewthwaite, Sarah, and Melanie Nind. "Teaching Research Methods in the Social Sciences: Expert Perspectives on Pedagogy and Practice.” British Journal of Educational Studies 64, no. 4 (June 28, 2016): 413-430. doi:10.1080/00071005.2016.1197882.

[8] Alharbi, Ahlam. "Book Review: Catherine Dawson, 100 Activities for Teaching Research Methods." Qualitative Research 17, no. 5 (October 2017): 600-602. doi:10.1177/1468794116683995.

[9] Mullins, Mary H. “Actively Teaching Research Methods with a Process Oriented Guided Inquiry Learning Approach.” Journal of Teaching in Social Work 37, no. 4 (August 8, 2017): 309-321. doi:10.1080/08841233.2017.1347122.

[10] Aguado, N. Alexander. "Teaching Research Methods: Learning by Doing." Journal of Public Affairs Education 15, no. 2 (June 2009): 251-260. doi:10.1080/15236803.2009.12001557.

[11] Alemanne, Nicole D., and Lauren H. Mandel. "Developing Research Practitioners: Exploring Pedagogical Options for Teaching Research Methods in LIS.” Journal of Education for Library and Information Science 59, no. 3 (July 2018): 26-40. doi:10.3138/jelis.59.3.2018-0015.04.

[12] Koufogiannakis, Denise, and Ellen Crumley. "Research in Librarianship: Issues to Consider." Edited by Su Cleyle. Library Hi Tech 24, no. 3 (July 2006): 324-340. doi:10.1108/07378830610692109.

[13] Thomas, Douglas, and John Seely Brown. A new culture of learning: Cultivating the imagination for a world of constant change. Vol. 219. Lexington, KY: CreateSpace, (2011).

[14] Schmidt, Henk G., Stephanie L. Wagener, Guus A.C.M. Smeets, Lianne M. Keemink, and Henk T. van der Molen. "On the Use and Misuse of Lectures in Higher Education." Health Professions Education 1, no. 1 (December 2015): 12-18. doi:10.1016/j.hpe.2015.11.010.

[15] Hosein, Anesa, and Namrata Rao. "Students' Reflective Essays as Insights into Student Centred-Pedagogies within the Undergraduate Research Methods Curriculum." Teaching in Higher Education 22, no. 1 (August 22, 2016): 109-125. doi:10.1080/13562517.2016.1221804.

[16] Nind, Melanie, and Sarah Lewthwaite. "Methods That Teach: Developing Pedagogic Research Methods, Developing Pedagogy." International Journal of Research \& Method in Education 41, no. 4 (January 22, 2018): 398-410. doi:10.1080/1743727x.2018.1427057.

[17] Steenkamp, Annette L., and Samual A. McCord. "Approach to teaching research methodology for information technology." Journal of Information Systems Education 18, no. 2 (2007): 255.

[18] Grover, Varun, and Kalle Lyytinen. "New State of Play in Information Systems Research: The Push to the Edges." MIS Quarterly 39, no. 2 (February 2, 2015): 271-296. doi:10.25300/misq/2015/39.2.01.

[19] Scholtz, B. An investigation into best practice approaches for computing research programmes in South Africa in 48th Annual Conference of the Sothern African Computer Lecturers Association (SACLA), Drakensburg, South Africa (2019).

[20] Gunn, Andrew. "Critical Debates in Teaching Research Methods in the Social Sciences." Teaching Public Administration 35, no. 3 (May 25, 2017): 241-259. doi:10.1177/0144739417708837.

[21] Mathur, A., "Teaching research to Media Students: A pedagogical Framework.” International Journal of Research and Analytical Reviews, 2019. 6(3): p. 293 - 307.

[22] Mekonnen, Fikru Debebe. "Evaluating the Effectiveness of' Learning by Doing 'Teaching Strategy in a Research Methodology Course, Hargeisa, Somaliland." African Educational Research Journal 8, no. 1 (2020): 13-19.

[23] Rapp-McCall, Lisa Ann, and Victoria Anyikwa. "Active Learning Strategies and Instructor Presence in An Online Research Methods Course: Can We Decrease Anxiety and Enhance Knowledge?” Advances in Social Work 17, no. 1 (April 25, 2016): 1-14. doi:10.18060/20871.

[24] Affouneh, Saida, Soheil Salha, and Zuheir N. Khlaif. "Designing quality e-learning environments for emergency remote teaching in coronavirus crisis." Interdisciplinary Journal of Virtual Learning in Medical Sciences 11, no. 2 (2020): 135-137.

[25] Bozkurt, Aras, and Ramesh C. Sharma. "Emergency remote teaching in a time of global crisis due to CoronaVirus pandemic." Asian Journal of Distance Education 15, no. 1 (2020): i-vi. doi:10.5281/zenodo.3778083. 
[26] Hodges, Charles, Stephanie Moore, Barb Lockee, Torrey Trust, and Aaron Bond. "The difference between emergency remote teaching and online learning." Educause review 27 (2020): 1-12.

[27] Guzman, M. "Preferred student-centered strategies in teacher education: Input to outcomes-based instruction." Asia Pacific Journal of Education, Arts and Sciences 3, no. 1 (2016): 40-48.

[28] Senanayake, Sanjeewanie H.D., Enosha Hettiarachchi, and Kamalanath P. Hewagamage. "Student-Centred Learning in a Blended Environment - Case Study Based on a Final Year Undergraduate Course.” 2015 Fifteenth International Conference on Advances in ICT for Emerging Regions (ICTer) (August 2015): 182-189. doi:10.1109/icter.2015.7377686.

[29] Ranjani, R. P. C., Susima Weligamage, W. V. A. D. Karunarathne, and P. N. D. Fernando. "Outcome-Based Education (OBE) using Student Centered Learning (SCL): The Case of Faculty of Commerce and Management Studies, University of Kelaniya, Sri Lanka." Association of Southeast Asian Institutions of Higher Learning (ASAIHL) Conference: Nanyang Technological University, Singapore (2014).

[30] Mitchell, Alanah, Stacie Petter, and A. L. Harris. "Learning by doing: Twenty successful active learning exercises for information systems courses." Journal of Information technology education: Innovations in Practice 16, no. 1 (2017): 21-46.

[31] Bonwell, Charles C., and James A. Eison. “Active Learning: Creating Excitement in the Classroom.” 1991 ASHE-ERIC Higher Education Reports. ERIC Clearinghouse on Higher Education, The George Washington University, One Dupont Circle, Suite 630, Washington, DC 20036-1183, 1991.

[32] Lea, Susan J., David Stephenson, and Juliette Troy. "Higher education students' attitudes to student-centred learning: beyond' educational bulimia'?." Studies in higher education 28, no. 3 (2003): 321-334. doi:10.1080/03075070309293.

[33] Nelson Laird, Thomas F., Rick Shoup, George D. Kuh, and Michael J. Schwarz. "The Effects of Discipline on Deep Approaches to Student Learning and College Outcomes." Research in Higher Education 49, no. 6 (February 12, 2008): $469-494$. doi:10.1007/s11162-008-9088-5.

[34] Mandel, Lauren. "Experiencing Research Firsthand: The 'unClassroom' Experiential Learning Approach to Teaching Research Methods in an LIS Master's Program.” Journal of Education for Library and Information Science Online 58, no. 4 (2017): 187201. doi:10.12783/issn.2328-2967/58/4/1.

[35] Weimer, Maryellen. "Learner-centered teaching: Five key changes to practice.” John Wiley \& Sons, 2002.

[36] Schutt, Russell K., Hubert M. Blalock, and Theodore C. Wagenaar. "Goals and Means for Research Methods Courses.” Teaching Sociology 11, no. 3 (April 1984): 235-258. doi:10.2307/1318304..

[37] Teoh, Sian Hoon, and Parmjit Singh A/l Aperar Singh. "A Practice in a Research Methodology Class." Asian Journal of University Education 15, no. 3 (December 31, 2019): 45-53. doi:10.24191/ajue.v15i3.7820..

[38] Pfeffer, Carla A., and Christabel L. Rogalin. “Three Strategies for Teaching Research Methods.” Teaching Sociology 40, no. 4 (May 16, 2012): 368-376. doi:10.1177/0092055x12446783.

[39] Sturm, B., S. Schneider, and A. Sunyaev, Leave no stone unturned: Introducing a revolutionary meta-search tool for rigorous and efficient systematic literature searches, in 23rd European Conference on Information Systems, Munster, Germany, (2015).

[40] Research discovery with artificial intelligence. 2020. Available online: https://iris.ai/ (accessed on September 2020).

[41] Daniel, Ben. "Reimaging Research Methodology as Data Science.” Big Data and Cognitive Computing 2, no. 1 (February 12, 2018): 4. doi:10.3390/bdcc2010004.

[42] Ross, Karen, and Meagan Call-Cummings. "Reflections on Failure: Teaching Research Methodology." International Journal of Research \& Method in Education 43, no. 5 (January 23, 2020): 498-511. doi:10.1080/1743727x.2020.1719060.

[43] Saunders, Mark, Philip Lewis, and Adrian Thornhill. "Research methods for business students." Pearson education, India, (2009).

[44] Venegas, Barbara Covarrubias, Gudrun Gaedke, and Barbara Geyer-Hayden. "Teaching Empirical Methods: Critical Reflection on Class Design and Blended Learning and Results of a Case Study on Competence Management." International Journal for Cross-Disciplinary Subjects in Education 3, no. 1 (March 1, 2012): 673-680. doi:10.20533/ijcdse.2042.6364.2012.0095. 